\title{
Margaret McCartney: Disrespecting confidentiality isn't the answer to FGM
}

The author of this column (BMJ 2015;351:h5830, doi:10.1136/ bmj.h5830), Margaret McCartney, would like to clarify her explanation of doctors' mandatory reporting duty for female genital mutilation (FGM) by noting that this duty does not apply where a woman aged 18 or over at the time of the consultation discloses she had FGM when she was under 18. The second sentence of the first paragraph should therefore read: "This new law compels healthcare professionals, social workers, and teachers to report to the police any cases of female genital mutilation (FGM) in girls or women aged under 18 (at the time of discovery) who appear to have had the procedure."

Cite this as: BMJ 2015;351:h6608

๑ BMJ Publishing Group Ltd 2015 